\title{
GLOBAL BIODIVERSITY PATTERNS OF BENTHIC MARINE ALGAE
}

\author{
Ailsa P. Kerswell ${ }^{1}$ \\ School of Marine Biology and Aquaculture and ARC Centre of Excellence for Coral Reef Studies, James Cook University, \\ Townsville, Queensland 4811 Australia
}

\begin{abstract}
Species richness patterns are remarkably similar across many marine taxa, yet explanations of how such patterns are generated and maintained are conflicting. I use published occurrence data to identify previously masked latitudinal and longitudinal diversity gradients for all genera of benthic marine macroalgae and for species in the Order Bryopsidales. I also quantify the size, location, and overlap of macroalgal geographic ranges to determine how the observed richness patterns are generated. Algal genera exhibit an inverse latitudinal gradient, with biodiversity hotspots in temperate regions, while bryopsidalean species reach peak diversity in the tropics. The geographic distribution of range locations results in distinct clusters of range mid-points. In particular, widespread taxa are centered within tight latitudinal and longitudinal bands in the middle of the Indo-Pacific and Atlantic Oceans while small-ranged taxa are clustered in peripheral locations, suggesting that variation in speciation and extinction are important drivers of algal diversity patterns. Hypotheses about factors that regulate diversity contain underlying assumptions about the size and location of geographic ranges, in addition to predictions as to why species numbers will differ among regions. Yet these assumptions are rarely considered in assessing the validity of the prevailing hypotheses. I assess a suite of hypotheses, suggested to explain patterns of marine diversity, by comparing algal-richness patterns in combination with the size and location of algal geographic ranges, to the richness and range locations predicted by these hypotheses. In particular, the results implicate habitat areas and ocean currents as the most plausible drivers of observed diversity patterns.
\end{abstract}

Key words: Bryopsidales; geographic range; hotspot; marine algae; ocean currents; richness gradients; species-area hypothesis.

\section{INTRODUCTION}

Global-scale patterns in species richness are one of the most studied phenomena in ecology, and consistent trends are repeatedly documented in both terrestrial and marine environments (Gaston 2000). The latitudinal gradient of increasing species richness from polar to tropical regions is arguably the most well known of these patterns, and few taxa display contrasting patterns (Willig et al. 2003). Longitudinal gradients, although less well studied, can also be distinct across individual continents and oceans (e.g., Jetz and Rahbek [2001] for birds, Roberts et al. [2002] for marine taxa). However, there is much controversy about the mechanisms that underlie the observed patterns of biodiversity, with upwards of 30 explanations for the latitudinal richness gradient alone (Rosen 1988, Willig et al. 2003).

Most theories that aim to explain the location of biodiversity hotspots typically rely on logical explanations for why one area will promote speciation or reduce extinction relative to another. For example, the species-area hypothesis suggests that larger areas can support more individuals and populations thereby

Manuscript received 24 January 2005; revised 31 March 2006; accepted 3 April 2006. Corresponding Editor: M. H. Carr.

${ }^{1}$ E-mail: ailsa.kerswell@jcu.edu.au reducing extinction risk, while also containing more barriers that promote allopatric speciation (Rosenzweig 1995, Chown and Gaston 2000). The species-energy hypothesis asserts that higher numbers of species in the tropics result from faster metabolic and speciation rates associated with warmer temperatures (Kaspari et al. 2004). Theories that revolve around climatic stability suggest that the tropics are a stable and relatively benign environment where species can specialize on predictable resources and persist when rare, compared to harsh temperate and polar regions where extinction rates are high (Hawkins et al. 2003). The species-productivity hypothesis suggests that greater energy inputs will support more individuals and promote specialization, although whether the relationship between species numbers and productivity is linear or hump shaped appears to be highly scale dependent (Rosenzweig 1995, Chase and Leibold 2002).

Recently mid-domain effect models have been proposed as biogeographic null models (Colwell and Lees 2000, Colwell et al. 2004). Under these models, speciesrichness gradients arise due to geometric constraints on the size and location of species' geographic ranges within a bounded domain in the absence of environmental factors. For species with wide ranges, the geometry of the domain has significant impact on species-richness patterns in that their ranges are most likely to overlap in 
the center of the domain, resulting in high numbers of species in the mid-domain region. This has been demonstrated both for African birds and Indo-Pacific corals and reef fishes (Jetz and Rahbek 2001, Connolly et al. 2003). In contrast, small-ranging taxa can occur anywhere inside the domain boundaries. Under a middomain-effect null model, they should be uniformly distributed across the domain; however, in nature, small-ranging taxa frequently cluster in common locations. For example, small-ranging birds cluster in pockets along the margins of the African continent, peripheral to the middle of the domain (Jetz and Rahbek 2001). Small-ranging African Proteaceae also cluster away from the domain center in southern temperate regions (Laurie and Silander 2002). Such deviations from null-model predictions suggest the need to evaluate alternative causes of species richness patterns (Colwell et al. 2004).

To date, biogeographic studies of benthic marine macroalgae have been restricted to regional scales, with little synthesis of worldwide trends. Japan, southern Australia, and western Europe are consistently highlighted as regions of high algal diversity, with the polar oceans, west Africa, and southeast Pacific identified as depauperate areas (Silva 1992, Bolton 1994, Santelices and Marquet 1998). Searches for latitudinal gradients in algal richness have also been performed on regional scales, with the most extensive of these studies indicating possible temperate richness peaks along the coastlines of the Americas (Pielou 1978). There is some indication that the most widespread red algal genera have extremely large ranges that extend across entire oceanic domains (Joosten and van den Hoek 1986). Smallranging algal genera appear to be clustered in temperature latitudes along both the east and west coasts of the Americas (Pielou 1978). In contrast, Santelices and Marquet (1998) found some evidence of increasing range size towards higher latitudes along the European coastline.

Algal-distribution patterns and regional assemblage composition have been explained largely in terms of historical processes. Early studies of algal biogeography discuss present-day patterns as a direct result of tectonic changes over geological time and shifts in species ranges as sea levels and temperature regimes fluctuated (Joosten and van den Hoek 1986). Recently, Adey and Steneck (2001) developed a model that defines thermogeographic regions based on temperature and habitat area since the Pleistocene. They also define biogeographic regions based on the presence, abundance, and level of endemism of crustose coralline algae and find that the two definitions produce matching regions. This suggests that energy and habitat area play an important role in determining the present-day macroecological patterns observed for benthic marine algae.

The major aim of my present study was to quantify global and oceanic gradients in macroalgal diversity. On a global scale, macroalgae display diversity gradients with unique features, such as temperate richness peaks. To understand how such unique patterns are generated, I quantify the manner in which geographic ranges of individual taxa combine to produce the observed patterns. These analyses were performed on two levels - for all genera of benthic marine macroalgae and for species in the Order Bryopsidales, which is a group of predominantly reef-associated algae that is both well surveyed and taxonomically stable (Littler and Littler 2003). While hypotheses about the causes of diversity gradients predict a positive correlation between environmental variables and species numbers, they also contain underlying assumptions about how species' ranges are distributed within biogeographic realms (e.g., Chown and Gaston 2000). Yet patterns in the distribution of species' ranges are often neglected when searching for processes that create and maintain diversity patterns. Therefore, in this study I have investigated algal-richness patterns in the context of sizes and locations of algal geographic ranges in order to gain a more comprehensive understanding of the processes that determine marine diversity.

\section{Methods}

A global database of benthic marine-algae occurrence records was compiled from 191 species lists sourced from the primary literature (141 peer-reviewed papers, 23 books, and 14 university-published scientific reports). In total, the database contained 387 sites throughout the Atlantic, Indo-Pacific, and Southern Oceans, which spanned $140^{\circ}$ of latitude (see Appendix A for full list of references and corresponding sites). At each site, genus-level data were compiled for all fully marine macroalgae in the Classes Rhodophyceae, Phaeophyceae, and Chlorophyceae and species-level data were compiled for all algae in the Order Bryopsidales. Algae were entered under the taxonomic classification listed in Guiry et al. (2005). Drift specimens and records noted as questionable by species-list authors were excluded. The resulting database contained 1069 genera of marine algae and 388 species of Bryopsidales.

The occurrence database was interfaced with a geographic information system (GIS) (ESRI 1992). Each site and algal taxon were unique records, linked via $>45000$ occurrence records. Records were verified against the primary literature if a single point occurred in the tropics when all other points were in temperate areas (and vice versa) or if an isolated point occurred in any ocean basin where there were no other occurrence records (Atlantic, Pacific, and Indian Ocean basins). To err on the side of caution, such records were deleted unless special reference was made by the authors as to the veracity of the record (e.g., Sporochnus moorei in Hawaii [Abbott 2004]).

Genus and species ranges were constructed in the GIS. A range was defined by outlining the boundary of all sites at which an alga was reported to occur and was plotted on an equal-area projection base map. Ranges 
were not extended over vast oceanic expanses e.g., the east Pacific barrier, nor over areas for which reliable species lists could not be obtained, e.g., Antarctic Ocean (outer contours in Fig. 1a delineate the maximum range boundary). The area of the geographic range (in square kilometers) was determined for each taxon in the GIS and ranges were partitioned into Indo-Pacific and Atlantic elements for algae that occur in both oceans. Range-size frequency distributions are presented on logarithmic plots. Because a direct comparison of IndoPacific vs. Atlantic range sizes would be confounded by the vastly different areas of the two oceans, algal-range areas were also expressed as a proportion of the total area of each ocean. The distributions of standardized range sizes were then compared between oceans using two-sided Kolmogorov-Smirnov testing $\left(\mathrm{R}_{2.0 .1}\right.$; RDCT 2004). The size and location of species' geographic ranges were explored for all algal taxa by plotting the latitudinal and longitudinal range extent against the location of range midpoints. In order to clearly identify clustering of algae, mid-point analyses are presented as two-dimensional density plots $\left(\mathrm{R}_{2.0 .1}, \mathrm{kde} 2 \mathrm{~d}\right.$ function; RCDT 2004).

Diversity patterns of benthic marine algae were explored by generating contours of algal richness. An estimate of diversity at each of the 387 sites in the database was generated by summing the number of ranges that overlapped that site. Range-derived diversity estimates were then used to interpolate contours of genus and species richness using the Inverse Distance Weighted interpolator (ArcView 3.2a GIS, $0.5^{\circ}$ cells, nearest neighbour technique with 12 neighbors, thirdorder power, no barriers). Thus contours represent the maximum diversity of a region, within which local sites may have lower diversity.

Endemics were defined as taxa reported at only one location or with a geographic range size $<1 \times 10^{6} \mathrm{~km}^{2}$ for genera and $<0.5 \times 10^{6} \mathrm{~km}^{2}$ for species (cf. Hughes et al. 2002). The above areal cutoffs are smaller than $0.5 \%$ of the largest geographic range recorded for each group. The location of endemics was explored by producing contour maps of the number of endemic taxa occurring at sites across the Indo-Pacific and Atlantic oceans. Contours were generated using the Inverse Distance Weighted interpolator (as above). Range-derived estimates of richness and the number of endemics used to generate contour maps are available in Appendix A.

\section{Data quality control}

Two major challenges in biogeographic studies are changes and inconsistencies in taxonomic identification and the delineation of geographic ranges from a set of sampling locations at biogeographic scales. When analyzing data on biogeographic scales, small differences arising from human error are not likely to alter conclusions significantly (Brown et al. 1996). Nevertheless, I have implemented several strategies to minimize bias due to taxonomy and sampling effects in the delineation of geographic-range boundaries.

The taxonomic status of each genus/species was verified in AlgaeBase (Guiry et al. 2005; available online). ${ }^{2}$ Older taxonomic classifications were updated to reflect the name assigned by Guiry et al. (2005). Genus-level rather than species-level classifications were used to determine richness patterns of all benthic marine macroalgae. Genus-level classifications were deemed more robust to misidentification and changes in systematics, and patterns identified at the genus level are often matched by species level data (e.g., see Veron [1995] for corals). In order to directly compare richness patterns between a number of marine groups, species-level patterns were analyzed for the Order Bryopsidales. The Bryopsidales were chosen due to their relative taxonomic stability (e.g., when plotting the number of new bryopsidalean species against time, the curve reaches an asymptote around 1970, with very few new species being described after this time; only $3 \%$ of the species lists pre-date 1970). Moreover, when patterns for the bryopsidales are analyzed at the broader genus level, the patterns are highly consistent with those generated by species-level data.

Sampling bias is an important concern when creating biogeographic ranges from species lists at particular locations, particularly when areas of high diversity coincide with areas that are traditionally well studied (Bolton 1994). However, very few taxa have been sufficiently intensively surveyed to generate global richness patterns based on occurrence records alone (Hurlbert and White 2005). An alternative method is to use geographic ranges to estimate richness across sites. This method is recognized as generating more realistic estimates of diversity than raw occurrence data, which tend to be more inconsistent and/or incomplete (McAllister et al. 1994), and has been used extensively for analyses conducted at continental to global scales (e.g., $80 \%$ of broad-scale studies on terrestrial plants, vertebrates, and invertebrates used range-derived richness estimates [Hawkins et al. 2003] as have several studies of corals and reef fishes [McAllister et al. 1994, Veron 1995, Bellwood et al. 2005]). Since the global effort of phycological study is patchy (Silva 1992, Bolton 1994), I used geographic ranges to estimate diversity at each site to minimize the bias associated with sampling effort. Furthermore, I tested for a dependence of algalgenus richness on either the number of sites or phycological studies in 14 regions worldwide. Linear regression showed no relationship between richness and either the number of sites $\left(P=0.47, \mathrm{R}_{2.0 .1}\right)$ or the number of phycological studies $\left(P=0.365, \mathrm{R}_{2.0 .1}\right)$ (see Appendix $\mathrm{B}$ for regions and regressions), indicating that genus richness was not merely a reflection of variation in sampling intensity.

\footnotetext{
${ }^{2}\langle$ http://www.algaebase.org $\rangle$
} 


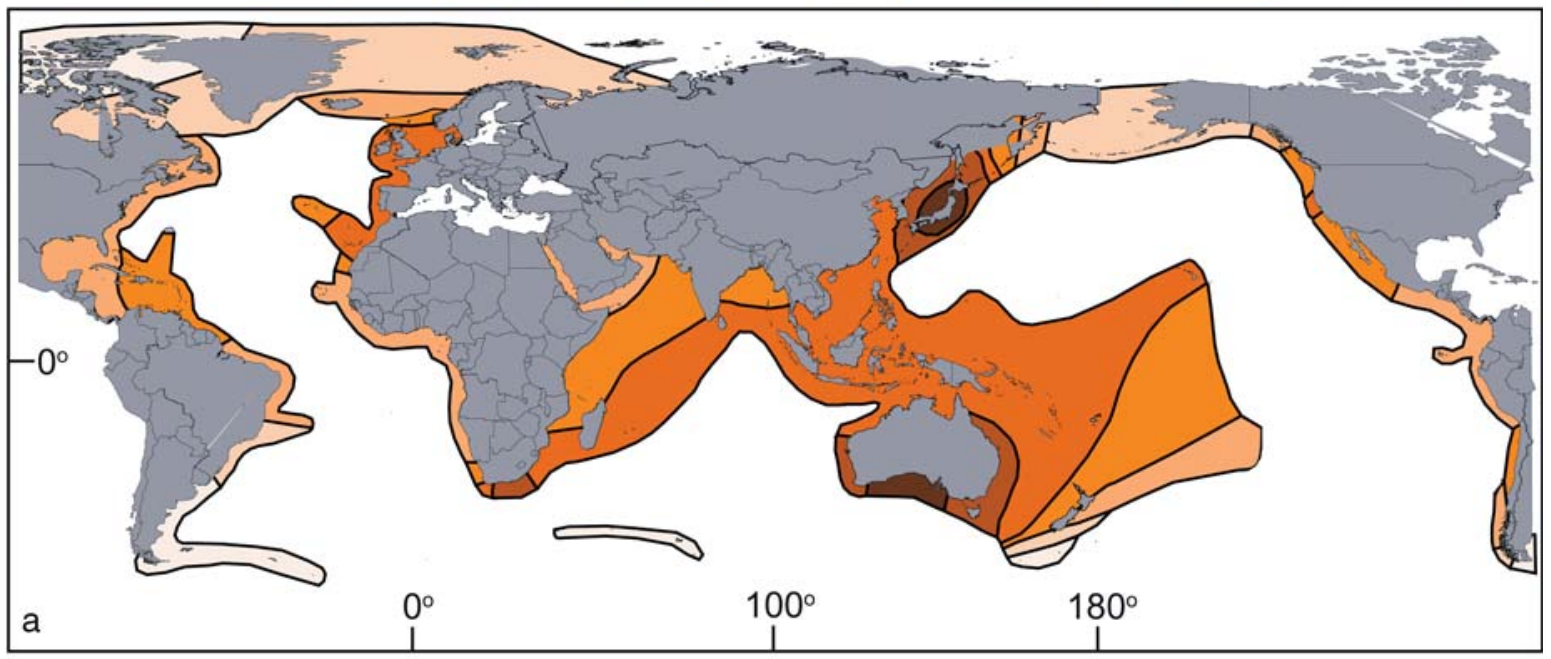

No. endemic genera 0 2

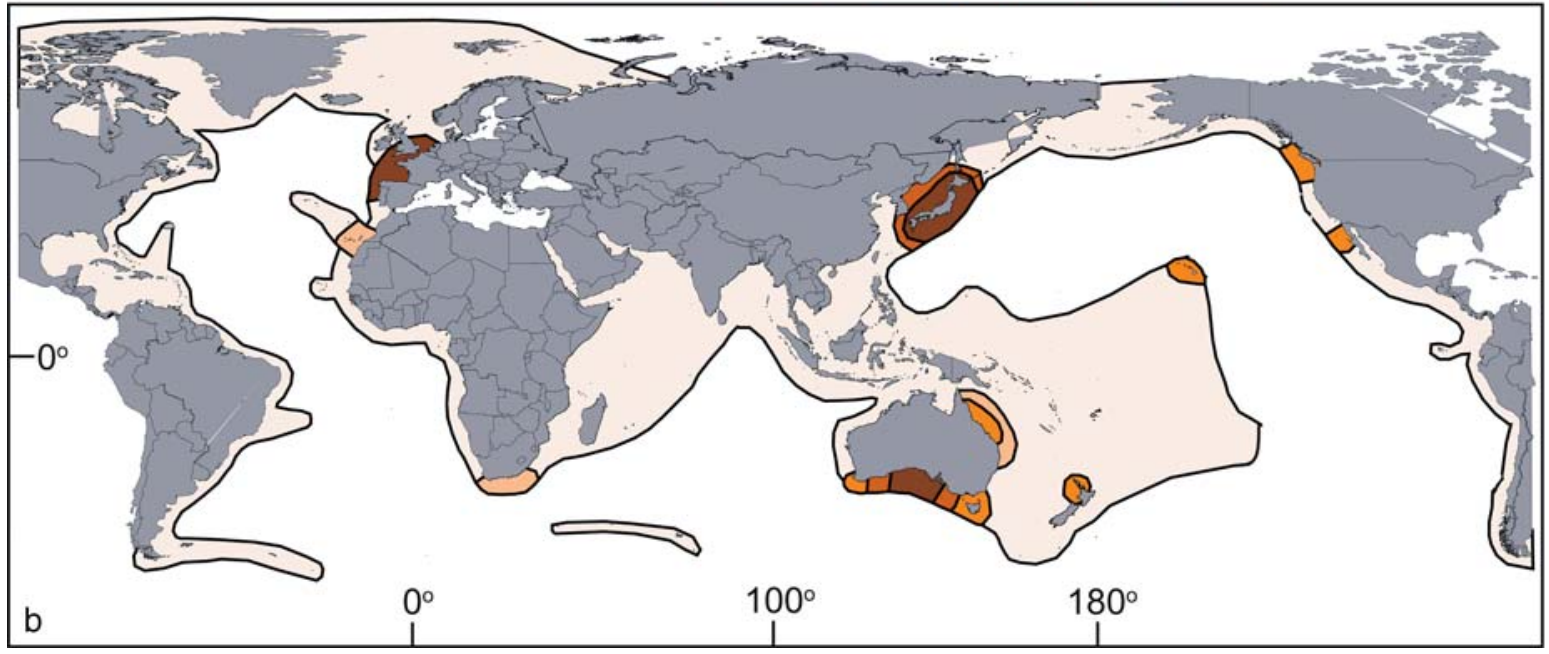

FIG. 1. Map of the Indo-Pacific and Atlantic Oceans showing contours of (a) algal genus richness and (b) clusters of endemic genera. Unshaded areas represent oceanic expanses or regions for which reliable data were not available.

\section{RESULTS}

\section{Centers of diversity and endemism}

Centers of genus diversity for benthic marine algae occur in temperate oceans. In the Indo-Pacific Ocean, centers of diversity occur in southern Australia and Japan, each containing 350-450 genera of algae (Fig. 1a). The Indo-Australian Archipelago (IAA) and southern Indian Ocean have moderate richness of $\sim 250-300$ genera. Thus, there is a band of high algal diversity running longitudinally between $110^{\circ}$ and $160^{\circ} \mathrm{E}$. Richness attenuates to the east and west of this band, reaching $\sim 150$ genera in the Red Sea and along the Chilean coastline. The areas of lowest diversity occur in the polar regions where fewer than 100 genera have been recorded. Algal-richness gradients in the Atlantic Ocean are both latitudinally and longitudially asymmetrical. The eastern coastline has higher diversity than the west, with the major Atlantic biodiversity hotspot located along the European coastline, extending south to Morocco (250-300 genera). Additionally, twice as many genera occur in the northern vs. the southern Atlantic. Endemic algal genera cluster in areas of high diversity within the respective oceans (Fig. 1b). At most of the 387 sites across both the Indo-Pacific and Atlantic Oceans, there are fewer than two endemic genera; however, this number increases to as many as 21 genera inside the Japan biodiversity hotspot. Endemic genera comprise $<6 \%$ of the flora at any site, including those within biodiversity hotspots.

In contrast to the patterns of all algal genera, centers of diversity for the Order Bryopsidales are located in the 


\section{No. Bryopsidales species $0 \square 15$
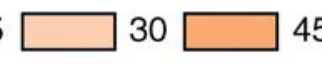 \\ $45 \square 60$ \\ $\square 75$ \\ $75 \square 90$ \\ 105}

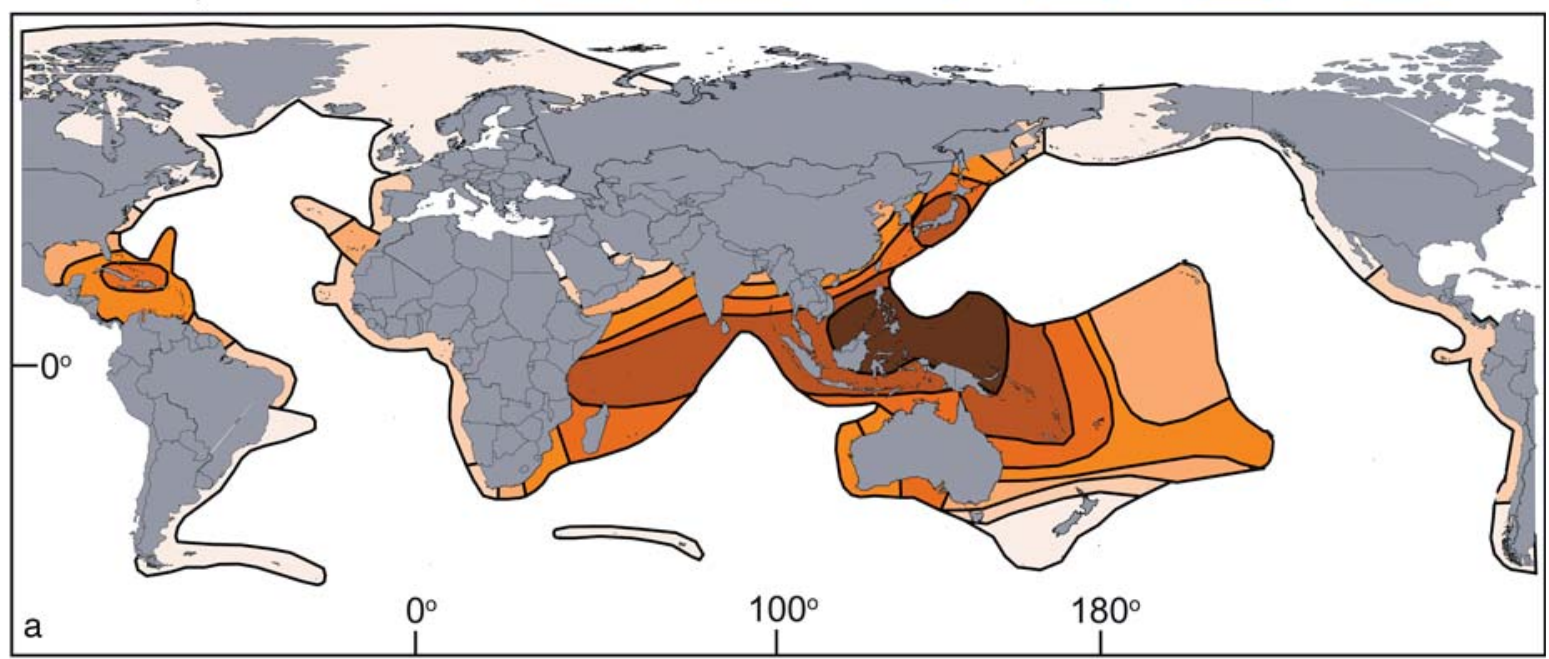

No. endemic Bryopsidales species 0

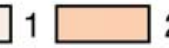

$2 \square$

$4 \square 6$

$6 \square 7+$

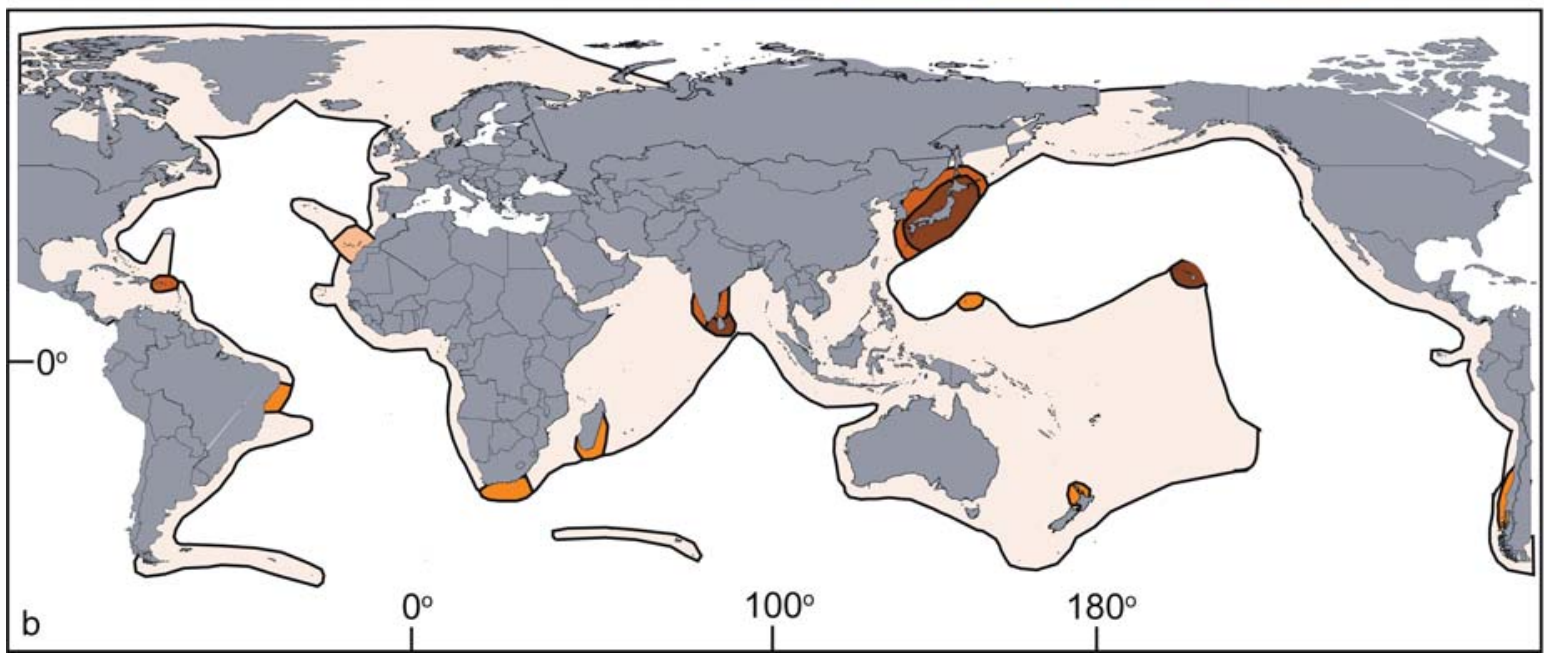

FIG. 2. Map of the Indo-Pacific and Atlantic Oceans showing contours of (a) species richness and (b) clusters of endemics within the Order Bryopsidales. Unshaded areas represent oceanic expanses or regions for which reliable data were not available.

tropics, and species richness diminishes both latitudinally and longitudinally away from these hotspots (Fig. 2a). In the Indo-Pacific, species richness is highest in the IAA, while the Atlantic Ocean center of diversity is located in the central Caribbean. However, diversity in the Atlantic is low, with the majority of areas containing $<30$ species compared to $>90$ species in the Indo-Pacific. While Indo-Pacific species endemics occur mainly outside areas of high diversity (in India, Japan, and Hawaii) most of the endemics in the Atlantic occur in the Caribbean, where species diversity is highest (Fig. 2b).

\section{Geographic range-size distributions}

Range-size frequency distributions (RSFD) are left skewed on a logarithmic scale (Fig. 3), highlighting the fact that many algae have very large geographic ranges. Endemics comprise a small proportion of the total number of genera in each ocean $(12 \%$ in the Indo-Pacific and $7 \%$ in the Atlantic). In contrast, $40 \%$ of Indo-Pacific and $33 \%$ of Atlantic genera have ranges $>10 \times 10^{6} \mathrm{~km}^{2}$ (i.e., ranges 10 times larger than endemics). A large percentage of bryopsidalean species are also wide ranging (44\% in the Indo-Pacific and $23 \%$ in the Atlantic have ranges $>5 \times 10^{6} \mathrm{~km}^{2}$, or 10 times the endemic range size). In contrast to genus-level patterns, endemic species are significant, with Bryopsidales comprising $23 \%$ and $20 \%$ of the Indo-Pacific and Atlantic flora, respectively.

There are significant differences between RSFDs of all algal genera and bryopsidalean species in the Indo- 

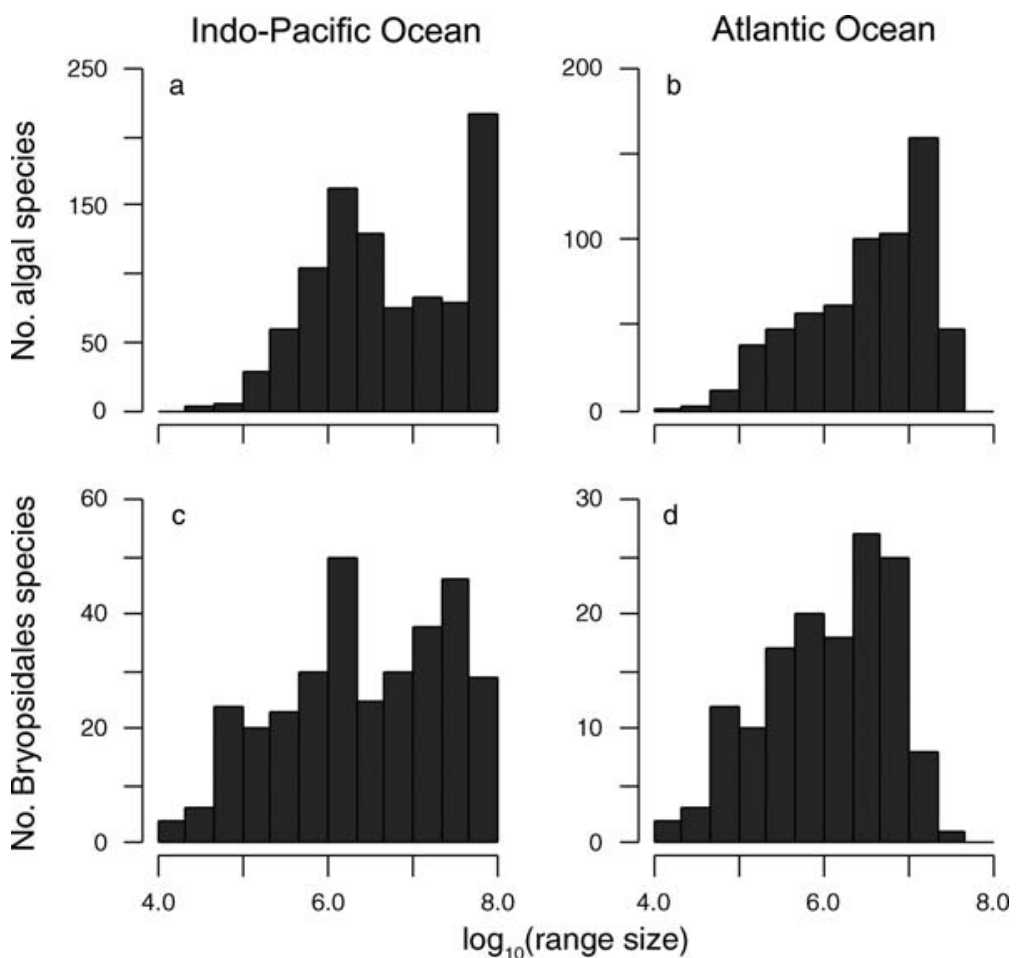

FIG. 3. Frequency distribution of geographic range size (RSFD) of all algal genera and bryopsidalean species in the IndoPacific (a and c) and the Atlantic Ocean (b and d); data have been log-transformed.

Pacific and Atlantic Oceans (genera: KolmogorovSmirnov $D=0.1814, P<0.001$; species: $D=0.150, P$ $=0.023)$. RSFDs in the Indo-Pacific are bimodal with peaks in the middle and the largest size classes (Fig. $3 \mathrm{a}, \mathrm{c})$. In the Atlantic, the proportion of algae in each range-size class increases from left to right (i.e., from small to large), but decreases sharply in the largest size categories (Fig. 3b, d).

\section{Location and overlap of geographic ranges}

There are striking patterns in the location and overlap of algal geographic ranges. Under a mid-domain effect null model, two-dimensional density plots of range extent vs. mid-point should be horizontally uniform within the triangular domain boundaries (Lees et al. 1999). Yet in both the Indo-Pacific and Atlantic Oceans, there is obvious clustering of algal ranges. In the IndoPacific, algal genera and species of Bryopsidales with large latitudinal extents cluster near the equator (Fig. $4 \mathrm{a}, \mathrm{c})$. In contrast, small-ranging genera cluster in both the northern and southern hemispheres away from the middle of the domain in temperate latitudes (Fig. 4a). Small-ranging Bryopsidales are spread throughout all latitudes of the Indo-Pacific with a cluster in the southern temperate region (Fig. 4c). Longitudinally, algal genera of small and large extent are centered in the middle of the Indo-Pacific between $110^{\circ}$ and $170^{\circ} \mathrm{E}$ (Fig. 4b). Longitudinally restricted Bryopsidales are also centered within this band, however, larger-ranging species are centered to the western side of the domain, leaving the eastern side relatively species poor (Fig. 4d).

The Atlantic Ocean is latitudinally highly asymmetrical, with the majority of genera and species having range midpoints north of the equator (Fig. 5a, c). Algae with large latitudinal extents are centered around $10^{\circ} \mathrm{N}$, while latitudinally restricted genera occur predominantly around $50^{\circ} \mathrm{N}$ in the temperate ocean. A large proportion of small-ranging Bryopsidales have latitudinal midpoints centered in the northern hemisphere tropics $\left(\sim 20^{\circ} \mathrm{N}\right)$. There is a striking contrast between the longitudinal clustering of genera and species in the Atlantic Ocean. The majority of genera are centered in the middle of the Atlantic domain, while most species of Bryopsidales have ranges centered on either the eastern or western ocean margins (Fig. 5b, d).

\section{Discussion}

\section{Marine biodiversity patterns}

Latitudinal and longitudinal gradients.-Diversity maps of the global distribution of benthic marine algae reveal distinct gradients in species and genus richness. Prior to this analysis, the documentation of latitudinal gradients in algal diversity was restricted to small regional scales (Pielou 1978, Santelices and Marquet 1998), leading to speculation that macroalgae do not exhibit global latitudinal gradients (Willig et al. 2003). The results of my study clearly show that this is not the case. In the largely reef-associated Order Bryopsidales, 
FIG. 4. Density plots of range extent and range midpoint location for the algal genera (a and b) and bryopsidalean species (c and d) in the Indo-Pacific Ocean. Dark areas represent high concentrations of midpoints, while in white areas there are very few midpoints. Triangles indicate domain boundaries (as per mid-domain effect; Colwell and Lees 2000).
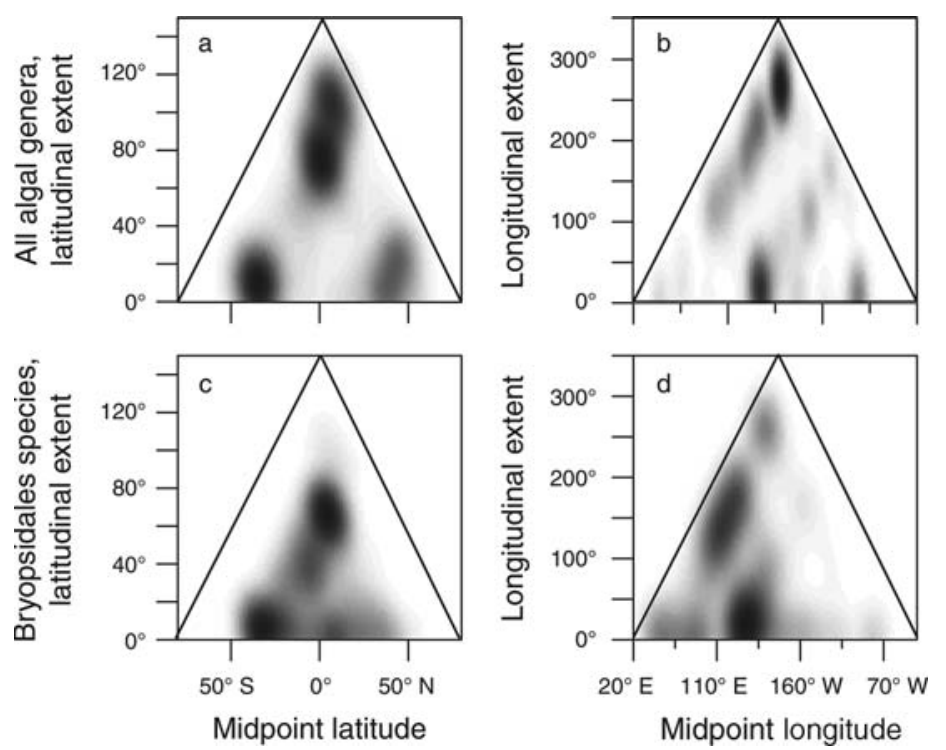

diversity peaks at tropical latitudes and decreases steadily towards the poles, in a manner well documented for other tropical marine organisms (Rosen 1988). However, when all algal genera are considered, temperate regions consistently have higher algal richness than tropical areas. In both the Indo-Pacific and Atlantic Oceans, algal centers of diversity occur in temperate areas, with richness decreasing towards the tropics and polar regions. Interestingly, this trend was also identified by early studies using more geographically restricted data sets (Pielou 1978, Vermeij 1978, Gaines and Lubchenco 1982). The peak in algal genus richness at mid-latitudes on a global scale makes benthic marine algae an exceptional group, in that there are very few taxa that have diversity peaks outside of the tropics (Willig et al. 2003).

Marine algae also display distinct longitudinal richness gradients. In the Indo-Pacific, algal richness peaks at the same longitudes as the richness of many other taxa (Rosen 1988, Roberts et al. 2002), resulting in a band of exceptionally high diversity between $110^{\circ}$ and $160^{\circ}$ E. Similarly in the Atlantic, the Order Bryopsidales, along with many other coastal marine taxa (Macpherson 2002), reaches peak richness on the tropical western coastline. However, when all algal genera are considered, the greatest diversity occurs on the eastern Atlantic coastline. While this is not unique within temperate regions (Macpherson 2002), the richness of the northeastern coast is usually significantly less than that of the
FIG. 5. Density plots of range extent and range midpoint location for the algal genera (a and b) and bryopsidalean species (c and d) in the Atlantic Ocean. Dark areas represent high concentrations of midpoints, while in white areas there are very few midpoints. Triangles indicate domain boundaries (as per mid-domain effect; Colwell and Lees 2000).
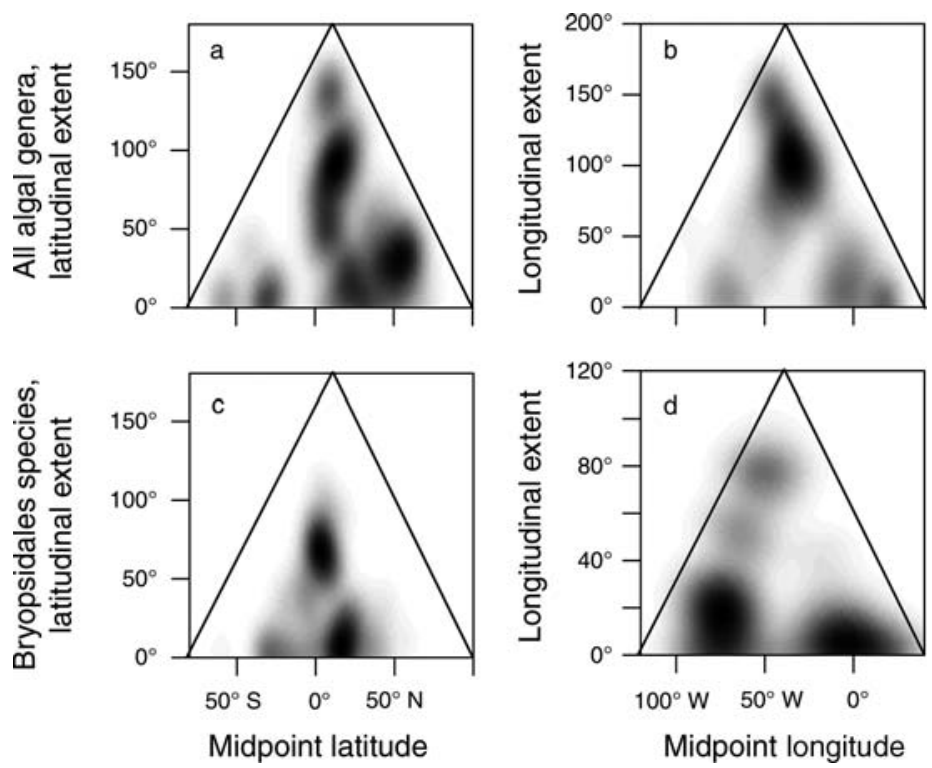
tropical Caribbean. That is clearly not the case for algal genera, further highlighting the exceptional nature of global algal-diversity patterns.

Size and location of geographic ranges.-Patterns in the size and location of geographic ranges can provide insights into the mechanisms regulating diversity that are unavailable solely from examining variations in species numbers across a biogeographic realm. Endemic algae occur throughout the Indo-Pacific and Atlantic Oceans and yet represent only a minor element of the total flora at any site. This is in stark contrast to many terrestrial systems, where diversity hotspots are generated largely by an accumulation of endemic taxa (Myers et al. 2000). Furthermore, in the Indo-Pacific, bryopsidalean endemics tend to be clustered outside of the Indo-Australian Archipelago (IAA) hotspot, in more peripheral depauperate locations, which is consistent with patterns documented for coral and reef-fish endemics (Hughes et al. 2002, Paulay and Meyer 2002, contra Mora et al. 2003).

It is also important to consider the observed size and location of ranges in comparison to an appropriate null expectation. Where deviations from such an expectation occur may provide further insight into mechanisms that regulate diversity patterns (Colwell et al. 2004). For example, in the Atlantic Ocean, large-ranged taxa are clustered in the center of the ocean and small-ranged taxa on the eastern and western boundaries. The geometry of the Atlantic Ocean does not allow these taxa to be located anywhere else, and thus no other explanation of richness patterns need be invoked. However, algal ranges are located predominantly in the northern Atlantic, and in the Indo-Pacific largeranged algae are clustered within tight latitudinal limits in the middle of the domain while small-ranging taxa are disproportionately clustered away from the center in temperate areas. A similar clustering is also evident for Indo-Pacific corals and reef fishes (Connolly et al. 2003) and such distributions of range locations can be generated when environmental gradients are incorporated along with geometric constraints in process-based models (Connolly 2005). Thus, identifying deviations from patterns generated solely by geometric constraints provides a basis from which to assess environmental drivers of species- richness patterns.

\section{Causes of biodiversity patterns}

A consideration of patterns of algal richness and range size and location indicates that the climatestability, species-energy, and competition hypotheses are unlikely to be major drivers of algal richness patterns. The key assumption of the climatic stability hypothesis, that specialization in benign tropical habitat leads to a decline in range size towards low latitudes (Steven 1989), is clearly not reflected in either genus- or species-level patterns of algal range size. Furthermore, overall algal richness is not highest in the tropics where metabolic processes are thought to enhance speciation
(Kaspari et al. 2004). Competition with corals is commonly cited as an explanation of lower algal richness in the tropics relative to temperate regions (e.g., Fraser and Currie 1996, Miller and Hay 1996). However, bryopsidalean richness peaks in the tropics in a manner very similar to corals (compare Fig. 2a with coral-richness patterns in Roberts et al. 2002). Bryopsidales are predominantly reef-associated algae and are likely to be in direct competition with corals for space (Littler and Littler 2003).

While the nature of the productivity-diversity relationship is highly scale dependent (Chase and Leibold 2001), there appears to be little evidence for productivity as a driver of macroalgal diversity at a global scale. Phytoplankton net primary productivity (NPP) is greatest at high latitudes in the northern hemisphere, along western continental boundaries, and in the subtropical convergence zone, due primarily to enhanced nutrient availability associated with major oceanic upwelling (Field et al. 1998, Behrenfeld et al. 2001). While the three centers of algal-genus richness are all located within these areas of peak productivity, areas of high NPP also encompass regions of both moderate (e.g., southern Africa and California) and low (e.g., Chile and New Zealand) algal richness. Moreover, oceanic productivity is very low in the Caribbean basin and the IAA where bryopsidalean richness is greatest.

The species-area hypothesis can explain some, but not all, of the global patterns of algal richness. Bryopsidalean species-richness patterns closely mirror those of corals and reef fishes, suggesting a common regulatory mechanism. Recently, the area of coral reef has been shown to account for a large proportion of the variation seen in coral and reef-fish richness patterns (Bellwood et al. 2005). Within temperate areas, regions of highest algal richness also coincide with large areas of suitable habitat (Silva 1992). However, while the species-area hypothesis can account for the location of peaks in both algal genus and species richness, it cannot explain why temperate hotspots support more genera than do equivalent tropical regions.

Major ocean currents may play an important role in determining the location of algal-richness hotspots through propagule dispersal and alteration of oceanic conditions. Ocean gyres flow clockwise in the northern hemisphere and counterclockwise in the southern hemisphere and, as a result, surface circulation in tropical regions is dominated by westward flowing equatorial currents. These currents leave the tropics, travelling poleward along western ocean boundaries and back towards the tropics along the eastern edges. If currents are influential in determining richness patterns through dispersal, then the greatest richness of tropical algae should occur in western ocean regions along with depauperate tropical floras in the east. Furthermore, if equatorial currents extend the geographic ranges of tropical algae into temperate regions, then high overall algal richness will occur where tropical and temperate 
floras overlap. This will be most prominent on the western ocean margins where both tropical and temperate floras are species rich compared to the eastern margins where tropical floras are depauperate. Currentdriven richness patterns should also result in distinct patterns of range size. Ranges of tropical algae centered at low latitudes are expected to be large and the ranges of algae that originate in temperate regions small, as temperate to tropical dispersal will be restricted.

The richness and range-size patterns observed for algae in the Indo-Pacific Ocean are consistent with those predicted in an ocean-currents-driven system. An exception is the high diversity of tropical Bryopsidales in the eastern Indian Ocean, which is unexpected under an ocean-gyres model. However, the coastal east-Indian Ocean is not dominated by the northward flowing Indian Ocean gyre. Rather, the tropical Leeuwin Current flows from the equator towards the south pole along the east-Indian ocean margin (west Australian coastline), on the inside of the northward flowing Indian Ocean gyre. Furthermore, the Leeuwin Current flows directly into the south Australian temperate hotspot from equatorial regions. Similar mechanisms have been suggested to influence richness patterns of corals and reef fishes (Connolly et al. 2003). Thus currents in the Indo-Pacific appear to play a role in creating and maintaining algal hotspots in temperate regions, where tropical and temperate floras overlap.

Algal richness is low throughout the southern Atlantic, however, unlike the southern Indo-Pacific, the influence of equatorial currents is only modest compared to sub-polar currents and upwelling systems (Pickard and Emery 1990). In the tropical Atlantic, Bryopsidales species richness is highest in the western ocean (Caribbean) as expected, however, overall genus richness peaks in the northeastern temperate regions. The north Atlantic is dominated by the Gulf Stream, which originates in western tropical regions and then flows north and east into temperate areas. Water originating in the tropics extends across the north Atlantic and flows north to Scotland and south to Africa (Pickard and Emery 1990), where algal richness is highest. In contrast, the low-diversity northwest Atlantic coasts are dominated by the Labrador current, which originates in the Arctic and extends south to Cape Hatteras $\left(\sim 35^{\circ} \mathrm{N}\right)$ (Pickard and Emery 1990). Hence ocean currents also appear to influence algal-richness patterns in the Atlantic Ocean.

\section{Conclusions}

This study provides the first worldwide assessment of patterns in algal richness that incorporates a quantification of the size and location of algal geographic ranges. Macroalgal genera show atypical latitudinal richness gradients, and this trend is consistent across oceans and biogeographic realms, suggesting that it is truly an exceptional global phenomenon rather than a regional anomaly. Hypotheses about the causes of diversity gradients generally assume a straightforward positive correlation between environmental variables and the number of taxa found at sites along that gradient. However, underlying these theories are fundamental assumptions about the relationship between the environmental variables and the size and location of species' geographic ranges (Stevens 1989, Chown and Gaston 2000). Yet patterns of geographic range size and location are rarely considered as evidence for or against the various hypotheses. When they are, we gain additional insights into the drivers of richness patterns that would have been unavailable from analyses of species numbers alone (Lees et al. 1999, Connolly 2003). This study explicitly quantifies both richness gradients and the distribution of range sizes and locations that give rise to those gradients. By conducting such analyses, especially for a group of organisms with exceptional richness gradients, important inroads have been made into gaining a more comprehensive understanding of how richness gradients are created and maintained.

\section{ACKNOWLEDGMENTS}

Many thanks to S. Connolly, T. Hughes, M. Kosnik, and three anonymous reviewers for their insightful comments on the manuscript, as well as to W. Huber for GIS advice.

\section{Literature Cited}

Abbott, I. A. 2004. Marine green and brown algae of the Hawaiian Islands. Bishop Museum Press, Honolulu, Hawaii, USA.

Adey, W. H., and R. S. Steneck. 2001. Thermogeography over time creates biogeographic regions: a temperature/space/ time-integrated model and an abundance-weighted test for benthic marine algae. Journal of Phycology 37:677-698.

Behrenfeld, M. J., J. T. Randerson, C. R. McClain, G. C. Feldman, S. O. Los, C. J. Tucker, P. G. Falkowski, C. B. Field, R. Frouin, W. E. Esaias, D. D. Kolber, and N. H. Pollack. 2001. Biospheric primary production during an ENSO transition. Science 291:2594-2597.

Bellwood, D. R., T. P. Hughes, S. R. Connolly, and J. E. Tanner. 2005. Environmental and geometric constraints on Indo-Pacific coral reef biodiversity. Ecology Letters 8:643651.

Bolton, J. J. 1994. Global seaweed diversity-patterns and anomalies. Botanica Marina 37:241-245.

Brown, J. H., G. C. Stevens, and D. M. Kaufman. 1996. The geographic range: Size, shape, boundaries, and internal structure. Annual Review of Ecology and Systematics 27: 597-623.

Chase, J. M., and M. A. Leibold. 2002. Spatial scale dictates the productivity-biodiversity relationship. Nature 416:427-430.

Chown, S. L., and K. J. Gaston. 2000. Areas, cradles and museums: the latitudinal gradient in species richness. Trends in Ecology and Evolution 15:311-315.

Colwell, R. K., and D. C. Lees. 2000. The mid-domain effect: geometric constraints on the geography of species richness. Trends in Ecology and Evolution 15:70-76.

Colwell, R. K., C. Rahbek, and N. J. Gotelli. 2004. The middomain effect and species richness patterns: What have we learned so far? American Naturalist 163:E1-E23.

Connolly, S. R. 2005. Process-based models of species distributions and the mid-domain effect. American Naturalist 166: $1-11$.

Connolly, S. R., D. R. Bellwood, and T. P. Hughes. 2003. IndoPacific biodiversity of coral reefs: deviations from a middomain model. Ecology 84:2178-2190. 
ESRI [Environmental Systems Research Institute]. 1992. ArcView 3.2a. ESRI, Redlands, California, USA.

Field, C. B., M. J. Behrenfeld, J. T. Randerson, and P. G. Falkowski. 1998. Primary production of the biosphere: integrating terrestrial and oceanic components. Science 281: 237-240.

Fraser, R. H., and D. J. Currie. 1996. The species richnessenergy hypothesis in a system where historical factors are thought to prevail: coral reefs. American Naturalist 148:138159.

Gaines, S. D., and J. Lubchenco. 1982. A unified approach to marine plant-herbivore interatctions. II. Biogeography. Annual Review of Ecology and Systematics 13:111-138.

Gaston, K. J. 2000. Global patterns in biodiversity. Nature 405: 220-227.

Guiry, M. D., E. Nic Dhonncha, and F. Rindi. 2005. AlgaeBase version 3.0. World-wide electronic publication, National University of Ireland, Galway, Ireland. 〈http://www. algaebase.org $\rangle$

Hawkins, B. A., R. Field, H. V. Cornell, D. J. Currie, J. F. Guegan, D. M. Kaufman, J. T. Kerr, G. G. Mittelbach, T. Oberdorff, E. M. O'Brien, E. E. Porter, and J. R. G. Turner. 2003. Energy, water, and broad-scale geographic patterns of species richness. Ecology 84:3105-3117.

Hughes, T. P., D. R. Bellwood, and S. R. Connolly. 2002. Biodiversity hotspots, centres of endemicity, and the conservation of coral reefs. Ecology Letters 5:775-784.

Hurlbert, A. H., and E. P. White. 2005. Disparity between range map- and survey-based analyses of species richness: patterns, processes and implications. Ecology Letters 8:319327.

Jetz, W., and C. Rahbek. 2001. Geometric constraints explain much of the species richness pattern in African birds. Proceedings of the National Academy of Sciences (USA) 98:5661-5666.

Joosten, A. M. T., and C. van den Hoek. 1986. Worldwide relationships between red seaweed floras - a multivariate approach. Botanica Marina 29:195-214.

Kaspari, M., P. S. Ward, and M. Yuan. 2004. Energy gradients and the geographic distribution of local ant diversity. Oecologia 140:407-413.

Laurie, H., and J. A. Silander. 2002. Geometric constraints and spatial pattern of species richness: critique of range-based null models. Diversity and Distributions 8:351-364.

Lees, D. C., C. Kremen, and L. Andriamampianina. 1999. A null model for species richness gradients: bounded range overlap of butterflies and other rainforest endemics in Madagascar. Biological Journal of the Linnean Society 67: 529-584.

Littler, D. S., and M. M. Littler. 2003. South Pacific reef plants. Offshore Graphics, Washinton, D.C., USA.

Macpherson, E. 2002. Large-scale species-richness gradients in the Atlantic Ocean. Proceedings of the Royal Society of London B: Biological Sciences 269:1715-1720.
McAllister, D. E., F. W. Schueler, C. M. Roberts, and J. P. Hawkins. 1994. Mapping and GIS analysis of the global distribution of coral reef fishes on an equal-area grid. Pages 155-175 in R. I. Miller, editor. Mapping the diversity of nature. Chapman and Hall, London, UK.

Miller, M. W., and M. E. Hay. 1996. Coral-seaweed-grazernutrient interactions on temperate reefs. Ecological Monographs 66:323-344.

Mora, C., P. M. Chittaro, P. F. Sale, J. P. Kritzer, and S. A. Ludsin. 2003. Patterns and processes in reef fish diversity. Nature 421:933-936.

Myers, N., R. A. Mittermeier, C. G. Mittermeier, G. A. B. da Fonseca, and J. Kent. 2000. Biodiversity hotspots for conservation priorities. Nature 403:853-858.

Paulay, G., and C. Meyer. 2002. Diversification in the tropical pacific: comparisons between marine and terrestrial systems and the importance of founder speciation. Integrative and Comparative Biology 42:922-934.

Pickard, G. L., and W. J. Emery. 1990. Descriptive physical oceanography: an introduction. Pergamon Press, Oxford, UK.

Pielou, E. C. 1978. Latitudinal overlap of seaweed species: evidence for quasi-sympatric speciation. Journal of Biogeography 5:227-238.

RDCT [R Development Core Team]. 2004. R: a language and environment for statistical computing. R Foundation for Statistical Computing, Vienna, Austria. 〈http://www. R-project.org $\rangle$

Roberts, C. M., C. J. McClean, J. E. N. Veron, J. P. Hawkins, G. R. Allen, D. E. McAllister, C. G. Mittermeier, F. W. Schueler, M. Spalding, F. Wells, C. Vynne, and T. B. Werner. 2002. Marine biodiversity hotspots and conservation priorities for tropical reefs. Science 295:1280-1284.

Rosen, B. 1988. Progress, problems, and patterns in the biogeography of reef corals and other tropical marine organisms. Helgolander Meeresuntersuchungen 42:269-391.

Rosenzweig, M. L. 1995. Species diversity in space and time. Cambridge University Press, Cambridge, UK.

Santelices, B., and P. A. Marquet. 1998. Seaweeds, latitudinal diversity patterns and Rapoport's Rule. Diversity and Distributions 4:71-75.

Silva, P. 1992. Geographic patterns of diversity in benthic marine algae. Pacific Science 46:429-437.

Stevens, G. C. 1989. The latitudinal gradient in geographic range: how so many species co-exist in the tropics. American Naturalist 133:240-256.

Vermeij, G. J. 1978. Biogeography and adaptation. Harvard University Press, Cambridge Massachusetts, USA.

Veron, J. E. N. 1995. Corals in space and time: the biogeography and evolution of the Scleractinia. UNSW Press, Sydney, New South Wales, Australia.

Willig, M. R., D. M. Kaufman, and R. D. Stevens. 2003. Latitudinal gradients of biodiversity: pattern, process, scale, and synthesis. Annual Review of Ecology, Evolution, and Systematics 34:273-309.

\section{APPENDIX A}

A summary table of the algae-occurrence database (with species-list references) (Ecological Archives E087-150-A1).

\section{APPENDIX B}

A figure demonstrating the independence of richness estimates from sampling efforts (Ecological Archives E087-150-A2). 